\title{
Antibacterial activity of calcium hydroxide and chlorhexidine containing points against Fusobacterium nucleatum and Parvimonas micra
}

\author{
Andreas Rathke ${ }^{1}$ \\ Dominik Meisohle ${ }^{2}$ \\ Jens Bokelmann ${ }^{3}$ \\ Bernd Haller ${ }^{1}$
}

\section{ABSTRACT}

Objective: Up to $90 \%$ of the flora of an infected root canal consists of obligate anaerobic bacteria. However, most studies have centred on microaerophiles. This quantitative assay investigated the antibacterial effects against Fusobacterium nucleatum and Parvimonas micra of gutta-percha (GP) points containing either calcium hydroxide $\left(\mathrm{Ca}(\mathrm{OH})_{2}\right)$ or chlorhexidine $(\mathrm{CHX})$ compared to those of conventional GP points.

Methods: Standardized root canals were prepared in 192 bovine incisors. The canals were sterilized and then inoculated with one of two bacterial species ( $n=96$ teeth per bacterium). After anaerobic incubation at $37^{\circ} \mathrm{C}$, the inoculum was removed and the canals were filled with one of the three points. Control teeth were filled with a saline/serum mixture. After 0, 1, 4 and 8 days of anaerobic incubation, the numbers of viable bacteria (CFU/ml) were determined on both the points and the canal wall dentin. Six replicates were carried out for each experiment.

Results: None of the points completely eradicated the bacteria in the canal. GP+CHX was significantly more effective than $\mathrm{GP}+\mathrm{Ca}(\mathrm{OH})_{2}$ and $\mathrm{GP}\left(\mathrm{P}<.05\right.$ in each case). The inhibitory effect of $\mathrm{GP}+\mathrm{Ca}(\mathrm{OH})_{2}$ did not significantly differ from that of $G P(P>$.05). Compared to the controls, the antibacterial effect of the medicated points was reached initially.

Conclusion: Within the limitations of the in vitro model, the incorporation of commonly used medicaments in GP does not offer a long-lasting antibacterial advantage over non-medicated GP. (Eur J Dent 2012;6:434-439)

Key words: Gutta-percha; calcium hydroxide; chlorhexidine diacetate; Fusobacterium nucleatum; Parvimonas micra; root canal

1 Department of Operative Dentistry and Periodontology, University of UIm, GERMANY

2 Division of Oral Microbiology, Department of Operative Dentistry and Periodontology, University of UIm, GERMANY

${ }^{3}$ Dentist in Private Practice, Kirchheim unter Teck, GERMANY
- Corresponding author: Dr. Andreas Rathke Department of Operative Dentistry and Periodontology, University of Ulm, Albert-Einstein-Allee 11, 89081 UIm, GERMANY

Tel: +4973150064155

Fax: +4973150064102

Email: andreas.rathkeduniklinik-ulm.de 


\section{INTRODUCTION}

In microbiologic examinations of teeth with periapical inflammation, evidence of viable bacteria within the infected root canal and adjacent dentinal tubules is frequently found. ${ }^{1,2}$ One primary objective in endodontic treatment is the elimination of the bacterial flora in infected teeth. This is usually accomplished by chemo-mechanical preparation of the root canal along with the use of a temporary root-filling between the appointments. Calcium hydroxide $\left(\mathrm{Ca}(\mathrm{OH})_{2}\right)$ is considered to be the endodontic antimicrobial agent of choice for reducing bacteria. ${ }^{2,3}$ Chlorhexidine $(\mathrm{CHX}$ ) seems to be effective in controlling some microorganisms which are not sensitive to $\mathrm{Ca}(\mathrm{OH})_{2}{ }^{4,5}$ Due to its broad biocidal spectrum, $\mathrm{CHX}$ is effective against aerobic and anaerobic bacteria even if it is administered in low concentrations. ${ }^{6}$ However, the poor handling properties of the traditional application forms of $\mathrm{Ca}(\mathrm{OH})_{2}$ and $\mathrm{CHX}$, i.e. liquid suspension, paste or gel, might be one reason why such medicaments often fail to completely disinfect infected root canals. ${ }^{7}$ To minimize this problem the use of medicated points that contain the medicaments in a gutta-percha (GP) matrix has recently been recommended. ${ }^{8}$ The therapeutic ingredient is released on contact with moisture in the root canal ${ }^{8}$ and should therefore be active for a prolonged time.

Dentin and other substances present in the root canal in vivo can inhibit the antibacterial efficacies of medicaments. ${ }^{4,9}$ For example, $\mathrm{Ca}(\mathrm{OH})_{2}$ has been reported to completely disinfect Enterococcus faecalis in an in vitro model. ${ }^{10}$ Nevertheless, a review of clinical trials has suggested its limited effectiveness against root canal infections. ${ }^{3}$ To date, most of the studies using root canal inoculation models have tested the antibacterial activity of $\mathrm{Ca}(\mathrm{OH})_{2}$ and/or $\mathrm{CHX}$ against aerotolerant or microaerophilic species such as E. faecalis. ${ }^{8,10-13}$ Little is known about obligate anaerobes, although there are several cultivable species known which may serve as antimicrobial target cells. Furthermore, obligate anaerobic bacteria, such as the Gramnegative Fusobacterium nucleatum and the Grampositive Parvimonas micra lformerly Micromonas micros or Peptostreptococcus micros), account for up to $90 \%$ of the endodontic flora in the apical part of infected root canals. ${ }^{14}$ These species have been shown to survive even after the root canal has been permanently filled with GP points and a sealer. ${ }^{1,14}$

The aim of this in vitro study was to evaluate the antibacterial effects of GP points containing either additions of $\mathrm{Ca}(\mathrm{OH})_{2}$ or $\mathrm{CHX}$ in comparison to conventional GP points in a modified root canal model inoculated with monocultures of $F$. nucleatum and P. micra.

\section{MATERIALS AND METHODS}

Preparation of Specimens

Bovine, lower central incisors of the same age ( $n=192$ ) were cut at the level of the cementoenamel junction using a water-cooled diamond separating disk (Woco 50/Med, Conrad, Clausthal-Zellerfeld, Germany). Standardized root canals measuring 15 $\mathrm{mm}$ in length and $0.8 \mathrm{~mm}$ in diameter were drilled (Endoseal, Straumann, Basel, Switzerland) in the root dentin, parallel to the axis and the natural root canal of each incisor. The root canals were enlarged with ISO size 80 files (Micro-Mega, Besancon, France) and irrigated with $3 \mathrm{ml}$ of sterile anaerobic $0.9 \% \mathrm{NaCl}$. The apex of the roots was shortened with a water-cooled polishing machine (Woco SF 20, Conrad) until the root canal floor was thinned to $0.5 \mathrm{~mm}$. The prepared root specimens were autoclaved at $121^{\circ} \mathrm{C}$ for 20 minutes and placed in glass vessels containing a freshly prepared mixture of equal amounts of sterile anaerobic $0.9 \% \mathrm{NaCl}$ solution and bovine serum (B-2771, Sigma, Steinheim, Germanyl. The cervical part of the root specimens protruded from the medium (Figure 1).

\section{Inoculation and Medication}

The strains F. nucleatum American Type Culture Collection (ATCC) 10953 and P. micra ATCC 33270 were anaerobically incubated at $37^{\circ} \mathrm{C}$ in $10 \mathrm{ml}$ of a thioglycolate medium (Oxoid Ltd, Basingstoke, Hampshire, UKJ supplemented with $0.5 \mathrm{mg} / \mathrm{l}$ vitamin $\mathrm{K}$ and $5 \mathrm{mg} / \mathrm{l}$ hemin. After incubation over night, the suspensions were diluted 1:10 with fresh medium and further incubated up to an optical density at $600 \mathrm{~nm}\left(0 D_{600}\right)$ of 0.2 . With $2 \times 10^{7}$ colony-forming units (CFU) per milliliter, this corresponded to an early logarithmic growth phase. The sterile root canals were inoculated with $5 \mu \mathrm{l}$ of the bacterial suspension corresponding to $1 \times 10^{5}$ CFU ( $n=96$ teeth per bacterium). The anaerobic environment was produced by activating BBL GasPak 
Plus envelopes (Becton-Dickinson Microbiology Systems, Sparks, USA) in anaerobic jars (GasPak Jars, Becton-Dickinson Microbiology Systems), which were subsequently placed in an incubator at $37^{\circ} \mathrm{C}$ for 2 days. The inoculum was removed with a sterile micropipette. No additional washing step was performed. The root canals were immediately medicated either with ISO size 80 GP points containing ca $52 \% \mathrm{Ca}(\mathrm{OH})_{2}$ (Calcium Hydroxide Points, Lot number 489808, Roeko Coltène/Whaledent, Langenau, Germanyl or ca 5\% CHX diacetate (Activ Point, Lot number 399946, Roeko Coltène/ Whaledent) or filled with conventional ISO size 80 GP points (Lot number 049808, Roeko Coltène/ Whaledent). The production sterility of the points had been verified in earlier studies. ${ }^{15}$ Control teeth were filled with the sterile anaerobic $\mathrm{NaCl} /$ serum mixture.

\section{Sampling and Statistical Analysis}

After anaerobic incubation at $37^{\circ} \mathrm{C}$ for $0,1,4$ and 8 days, each root canal was enlarged with a sterile ISO size 90 file (Micro-Mega). Each file was placed in a sterile tube containing $1.5 \mathrm{ml}$ of sterile anaerobic $0.9 \% \mathrm{NaCl}$ solution. The capped tube was ultrasonicated for 1 minute and then placed in a centrifuge for 10 minutes at $8000 \mathrm{x}$ g. The sediment of dentinal shavings and bacteria was resuspended in $150 \mu \mathrm{l} \mathrm{NaCl}$. Following serial dilutions of $10^{-1}$ to $10^{-3}$ in $\mathrm{NaCl}, 100 \mu \mathrm{l}$ aliquots were plated onto agar plates and the numbers of CFU/ml were de-

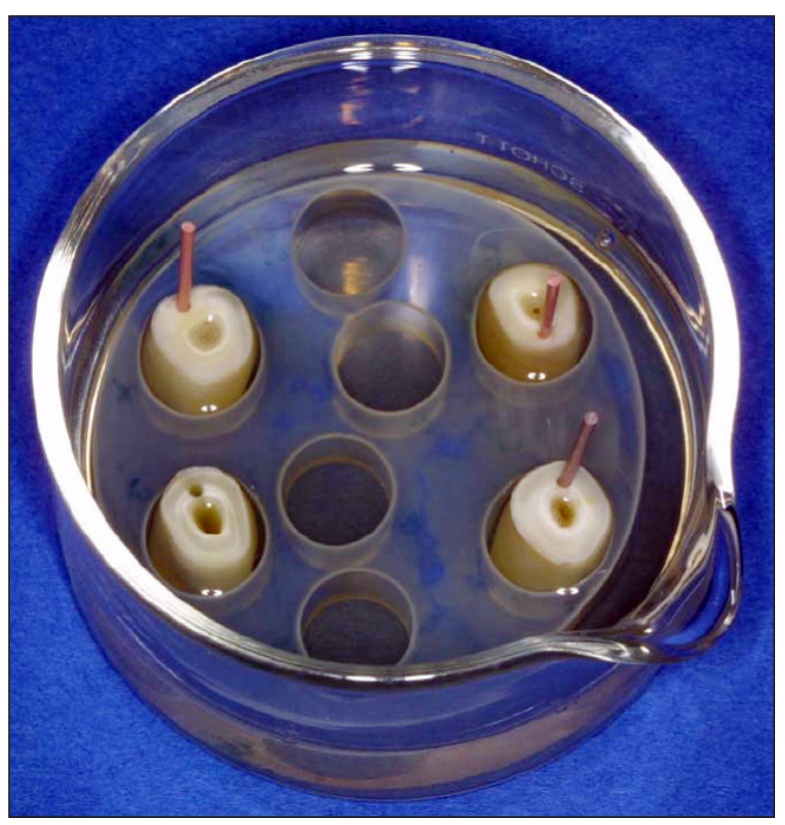

Figure 1. Experiments were carried out in glas jars filled with sterile anaerobic $\mathrm{NaCl}$ serum medium and containing the medicated and non-medicated root specimens as well as the bacterial growth controls. termined as previously described. ${ }^{16}$ At the selected time intervals, the points that had been removed were also transferred to sterile tubes containing $1.5 \mathrm{ml} \mathrm{NaCl}$ each. Again the numbers of $\mathrm{CFU} / \mathrm{ml}$ in subsequent dilutions were calculated. Six replicates were carried out for each experiment including the control group. Precautions were taken to ensure asepsis throughout the experiments and to keep the bacteria's exposition to oxygen as low as possible. Preliminary results confirmed that opening the incubation vials frequently and/or for long periods had an unacceptable influence on bacterial growth. ${ }^{17}$ Statistical analysis was performed with the nonparametric Kruskal-Wallis test, followed by the Mann-Whitney test. The resulting $P$ values were corrected by using the Holm procedure.

\section{RESULTS}

The antibacterial effect of the three different points against $F$. nucleatum and $P$. micra in the root canal is shown in Figures 2 and 3 . For both strains, growth controls showed no significant differences up to 8 days ( $P>$.05). After 1 day, bacterial cell counts in the root canals filled with $\mathrm{GP}+\mathrm{CHX}$ were significantly lower than in the other groups $(P<.05)$. However, the difference was no longer significant at day 8 for $P$. micra $(P>.05)$. The inhibitory effect of $\mathrm{GP}+\mathrm{Ca}(\mathrm{OH})_{2}$ did not significantly differ from that of GP alone or the growth control at any time interval $(P>$.05).

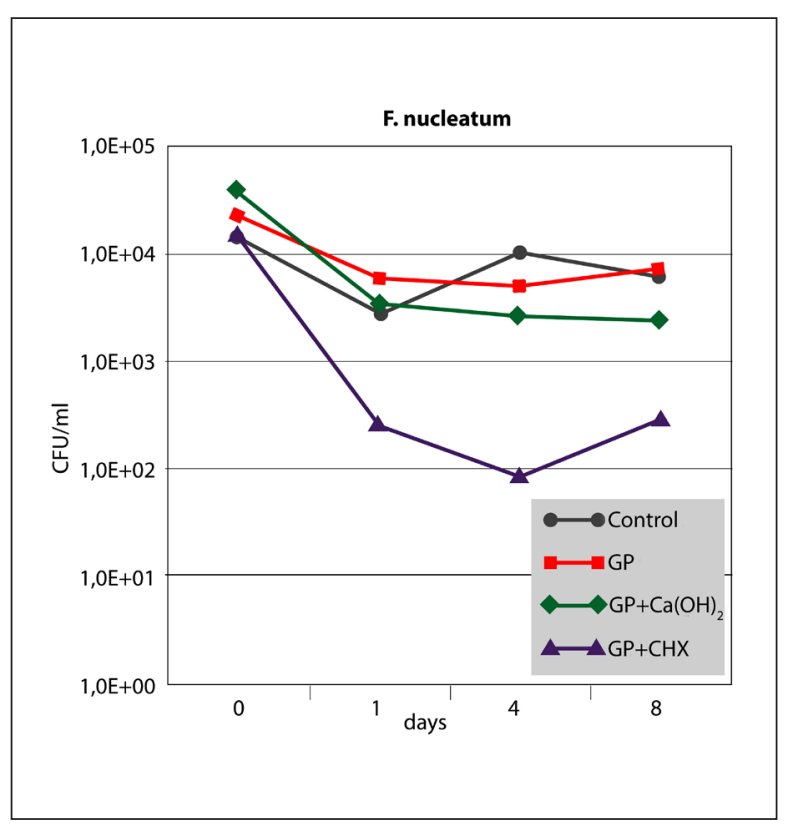

Figure 2. Median CFU/ml counts ( $\mathrm{n}=6$ ) of $F$. nucleatum sampled from inoculated root canals filled with three different points at different time intervals in comparison with the growth control (root canals without points). 
When F. nucleatum was sampled from the points, $\mathrm{GP}$ and $\mathrm{GP}+\mathrm{Ca}(\mathrm{OH})_{2}$ showed constant and high bacterial cell counts over the 8-day period. No significant differences could be observed $(P<.05)$. In contrast, GP+CHX showed lower cell counts after one day with bacterial growth increasing on the subsequent days (Figure 4). However, GP+CHX was significantly more effective than $\mathrm{GP}+\mathrm{Ca}(\mathrm{OH})_{2}$ or $\mathrm{GP}$ at any time $(P<.01)$. Sampling of $P$. micra from the points resulted in similar data (Figure 5). Significant differences were seen between $\mathrm{GP}+\mathrm{CHX}$ and

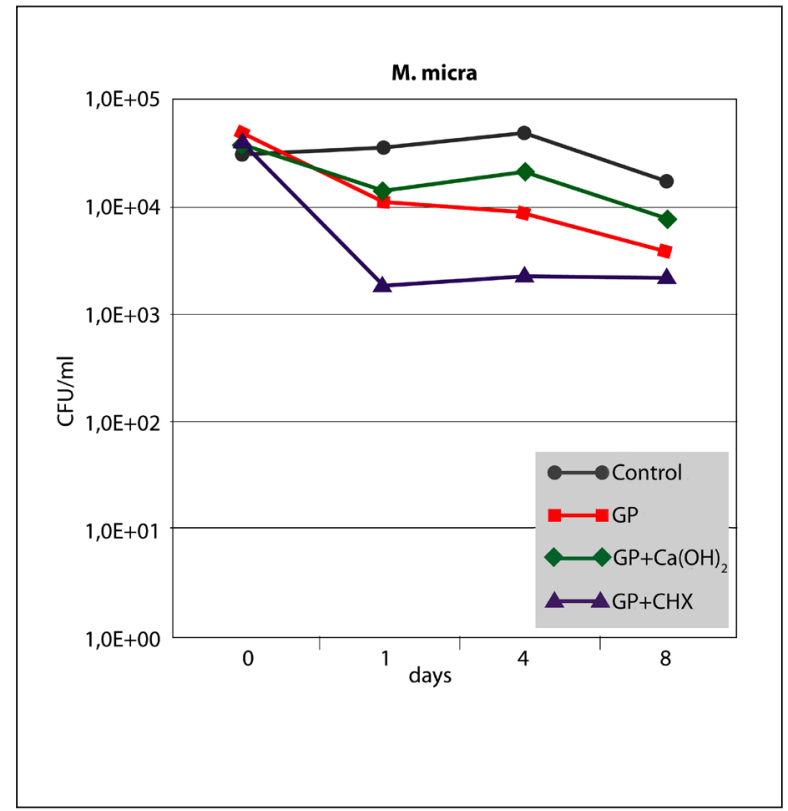

Figure 3. Median CFU/ml counts $(\mathrm{n}=6)$ of $P$. micra sampled from inoculated root canals filled with three different points at different time intervals in comparison with the growth control (root canals without points).

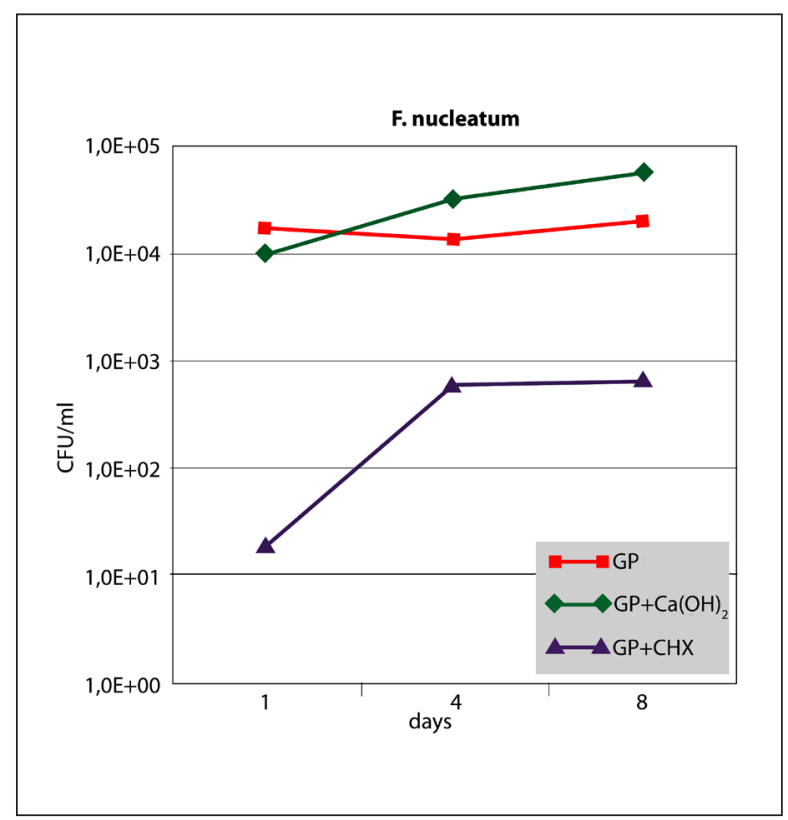

Figure 4. Median $\mathrm{CFU} / \mathrm{ml}$ counts $(\mathrm{n}=6)$ of $F$. nucleatum sampled from three different points at different time intervals.
$\mathrm{GP}+\mathrm{Ca}(\mathrm{OH})_{2} \quad(\mathrm{P}<.05)$. No significant differences were found between $\mathrm{GP}+\mathrm{Ca}(\mathrm{OH})_{2}$ and $\mathrm{GP}(\mathrm{P}>\mathrm{.05})$.

\section{DISCUSSION}

In this study, the root canal inoculation test originally described by Haapasalo and Ørstavik was modified to include a quantitative assay and to involve obligate anaerobes as the antimicrobial target cells. ${ }^{11}$ Due to the thick dentin layer of bovine incisors, the root canal could be standardized. The smear layer produced during root canal preparation was not removed by irrigation, as this could have distorted the effects of the medicaments. ${ }^{10}$ In clinical situations, the antibacterial effect of the medicated GP points may be higher when the root canals are irrigated. In this study, however, the root canals were seeded only for a short period of time. The resulting early phase biofilms are known to be rather susceptible to medicaments compared to a maturated biofilm involving complex microbial interactions. When the points tested were removed from the root canals, some of the bacteria were inevitably brushed off on the canal walls. The progressive reaming of the standardized root canal from ISO size 80 to 90 aimed to sample residual bacteria up to dentin depths of $100 \mu \mathrm{m}$ around the canal lumen. This approach of removing the canal wall dentin with sterile endodontic files and quantitatively determining the viable bacteria by plating the recovered dentin shavings has been described in previous studies. ${ }^{12,13}$ The fact that it was diffi-

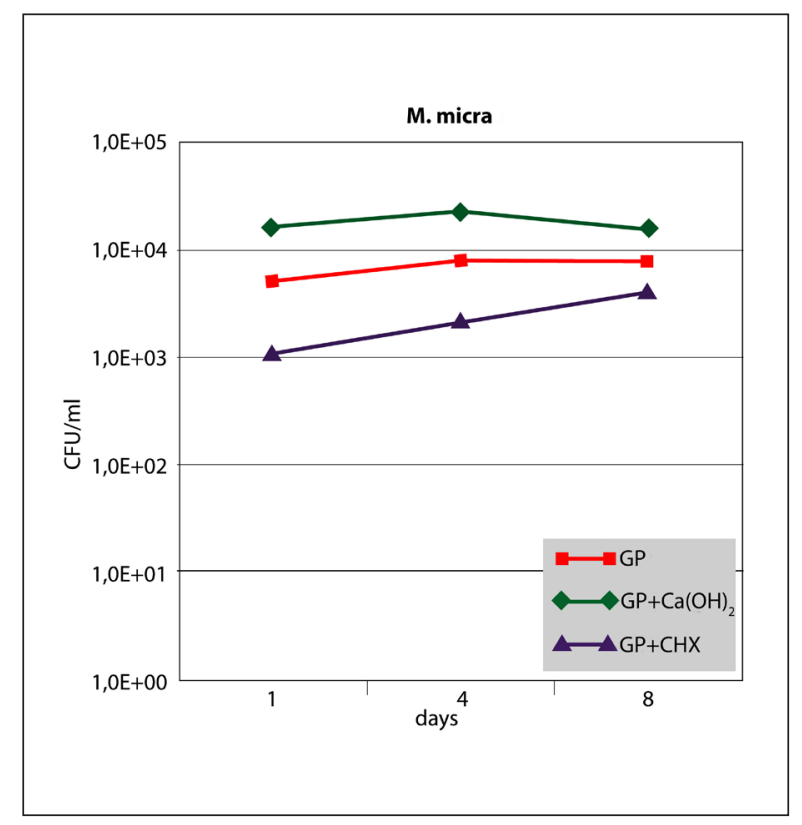

Figure 5. Median CFU/ml counts $(\mathrm{n}=6)$ of $P$. micra sampled from three different points at different time intervals. 
cult to standardize the amount of dentin removed may have contributed to the data variance. However, when the validity was considered, the bacterial samples taken from the root canal and the points showed comparable results. The numbers of CFU/ $\mathrm{ml}$ from the control teeth were almost constant over the 8-day period with a bacteria load similar to that which is found in a clinically infected root canal. 2,18 The results from the sampling of the growth control at 0, 1, 4 and 8 days after baseline showed that the viable counts of $F$. nucleatum and $P$. micra were not significantly affected by the short-term exposition of the bacteria to oxygen when the incubation vials were opened. ${ }^{17}$ Diluted serum was used to simulate the mixture of interstitial liquid and blood filtrate found in clinical situations ${ }^{5}$ and to allow any possible influences of plasma proteins on the medicaments (eg, buffering) to be taken into account. ${ }^{9}$ This $\mathrm{NaCl} /$ serum solution mixture also served as the growth control in earlier studies. 5,16,17

Although the bacterial strains used are type strains, they were originally isolated from sick humans. According to the information provided by the ATCC product sheet, $F$. nucleatum was isolated from the inflamed gingiva of an adult male and $P$. micra from a patient with purulent pleurisy. Therefore, they should be suitable for early assays for determining the antimicrobial potency of medicated GP points. However, these strains have been used in laboratories over a long period of time and might therefore have lost some of their pathogenic features. Therefore, freshly isolated clinical strains could enhance further tests and might lead to results differing from the present observations.

According to the present results, $\mathrm{CHX}$ medicated points were significantly more effective against F. nucleatum and $P$. micra than $\mathrm{Ca}(\mathrm{OH})_{2}$ containing points. This finding supports studies suggesting that $\mathrm{CHX}$ has a strong antibacterial effect in concentrations ranging from $0.12 \%$ to $5 \%$, 12 but contradicts the findings of others reporting similar efficacies for $\mathrm{CHX}$ and $\mathrm{Ca}(\mathrm{OH})_{2} \cdot{ }^{13,18}$ The discrepancies in the results may be due to variations in the study design, the concentration and/or the delivery form of the antimicrobial agent. It has been shown that gels with $5 \% \mathrm{CHX}$ are significantly more effective than $\mathrm{CHX}$ containing points. ${ }^{18}$ It was surmised that the active ingredients were released from the GP matrix very rapidly. This short-term release may constitute one of the reasons why in the pres- ent study, the maximum of the antibacterial effect of both $\mathrm{CHX}$ and $\mathrm{Ca}(\mathrm{OH})_{2}$ containing points was reached initially and decreased over the 8-day period.

The minor antibacterial effect of the $\mathrm{Ca}(\mathrm{OH})_{2}$ containing points in this study coincides with other findings. ${ }^{19,20}$ Measurements as a function of time revealed that within 1 day the major amount of $\mathrm{Ca}(\mathrm{OH})_{2}$ was released from the matrix and the concentration reached a saturation point. ${ }^{19}$ A significantly higher $\mathrm{pH}$ was only established in the immediate proximity of the $\mathrm{Ca}(\mathrm{OH})_{2}$ containing points after 1 day and could no longer be detected after 3 days. ${ }^{20}$ As a consequence, the alkalinity may not have been high enough to result in the eradication of bacteria. However, the delivery system does not seem to be the only factor that is responsible for the limited effectiveness. Although studies have found $\mathrm{Ca}(\mathrm{OH})_{2}$ to be more effective when applied as a paste, ${ }^{18,19}$ concern has grown about the limited effectiveness of $\mathrm{Ca}(\mathrm{OH})_{2}$ in general against some species frequently found in clinically infected canals. ${ }^{3}$ Despite the fact that there was no significant difference, the $\mathrm{Ca}(\mathrm{OH})_{2}$ containing points showed a less pronounced effect on $P$. micra than GP in this study. The ZnO of the GP matrix seems to have some antibacterial activity caused by the release of cytotoxic zinc ions. ${ }^{21} \mathrm{Nev}$ ertheless, the fact that chronic apical periodontitis often occurs in conjunction with inadequately filled root canals ${ }^{2}$ indicates that GP cannot be expected to lower the bacteria counts significantly in clinically treated root canals.

\section{CONCLUSION}

Under the limitations of the in vitro setting, our results suggest that GP loaded with ca $52 \% \mathrm{Ca}(\mathrm{OH})_{2}$ do not possess a long-lasting antibacterial advantage over the non-medicated GP. The incorporation of ca $5 \% \mathrm{CHX}$ in GP leads to an enhanced antibacterial effect against $F$. nucleatum and $P$. micra, at least in the short-term. However, factors not present in the root canal inoculation model may play an important role in the antimicrobial activity in vivo. Particularly, the multispecies communities of biofilms may promote increased resistance levels against antimicrobial agents.

\section{ACKNOWLEDGEMENTS}

The authors deny any financial affiliations related to this study. The authors thank Henry Frehse 
(Department of Operative Dentistry and Periodontology, University of U(m) for the preparation of the root specimens and Prof. Dr. Rainer Muche (Institute of Biometry, University of Ulm) for the statistical support.

\section{REFERENCES}

1. Gomes BP, Pinheiro ET, Gade-Neto C et al. Microbiological examination of infected dental root canals. Oral Microbiol Immunol 2004;19:71-76.

2. Blome B, Braun A, Sobarzo V, Jepsen S. Molecular identification and quantification of bacteria from endodontic infections using real-time polyermase chain reaction. Oral Microbiol Immunol 2008;23:384-390.

3. Sathorn C, Parashos P, Messer H. Antibacterial efficacy of calcium hydroxide intracanal dressing: a systematic review and meta-analysis. Int Endod J 2007;40:2-10.

4. Mohammadi Z, Abbott PV. Antimicrobial substantivity of root canal irrigants and medicament: a review. Aust Endod $J$ 2009;35:131-139

5. Podbielski A, Spahr A, Haller B. Additive antimicrobial activity of calcium hydroxide and chlorhexidine on common endodontic bacterial pathogens. J Endod 2003;29:340-345.

6. Yesilsoy C, Whitaker E, Cleveland D, Phillips E, Trope M. Antimicrobial and toxic effects of established and potential root canal irrigants. J Endod 1995;21:513-515.

7. Staehle HJ, Thomä C, Müller HP. Comparative in vitro investigation of different methods for temporary root canal filling with aqueous suspensions of calcium hydroxide. Endod Dent Traumatol 1997;13:106-112.

8. Ebert J, Roggendorf MJ, Frank K, Petschelt A. Antimicrobial activity of various 'active' gutta-percha points against Enterococcus faecalis in simulated root canals. Int Endod $J$ 2008;41:249-257

9. Portenier I, Waltimo T, Ørstavik D, Haapasalo M. Killing of Enterococcus faecalis by MTAD and chlorhexidine digluconate with or without cetrimide in the presence or absence of dentine powder or BSA. J Endod 2006;32:138-141.

10. Zehnder M, Luder H, Schatzle M, Kerosuo E, Waltimo T. A comparative study on the disinfection potentials of bioactive glass S53P4 and calcium hydroxide in contra-lateral human premolars ex vivo. Int Endod J 2006;39:952-958.

11. Haapasalo $M, \emptyset$ rstavik D. In vitro infection and disinfection of dentinal tubules. J Dent Res 1987;66:1375-1379.

12. Schäfer E, Bössmann K. Antimicrobial efficacy of chlorhexidine and two calcium hydroxide formulations against Enterococcus faecalis. J Endod 2005;31:53-56.

13. Lui JN, Sae-Lim V, Song KP, Chen NN. In vitro antimicrobial effect of chlorhexidine-impregnated gutta percha points on Enterococcus faecalis. Int Endod J 2004;37:105-113.
14. Sundqvist G. Taxonomy, ecology, and pathogenicity of the root canal flora. Oral Surg Oral Med Oral Pathol 1994;78:522530.

15. Seabra Pereira OL, Siqueira JF Jr. Contamination of guttapercha and Resilon cones taken directly from the manufacturer. Clin Oral Investig 2010;14:327-330.

16. Rathke A, Staude R, Muche R, Haller B. Antibacterial activity of a triclosan-containing resin composite matrix against three common oral bacteria. J Mater Sci Mater Med 2010;21:2971-2977.

17. Spahr A, Lyngstadaas SP, Boeckh C, Andersson C, Podbielski A, Haller B. Effect of enamel matrix derivate Emdogain on the growth of periodontal pathogens in vitro. J Clin Periodontol 2002;29:62-72.

18. Barthel CR, Zimmer S, Zilliges S, Schiller R, Göbel UB, Roulet JF. In situ antimicrobial effectiveness of chlorhexidine and calcium hydroxide: gel and paste versus guttapercha points. $J$ Endod 2002;28:427-430.

19. Economides N, Koulaouzidou EA, Beltes P, Kortsaris AH. In vitro release of hydroxyl ions from calcium hydroxide guttapercha points. J Endod 1999;25:481-482.

20. Schäfer $E$, Al Behaissi A. ph changes in root dentin after root canal dressing with gutta-percha points containing calcium hydroxide. J Endod 2000;26:665-667.

21. Silver S. Bacterial resistance to toxic metal ions - a review. Gene 1996;179:9-19. 